\title{
TRANSVALVULAR TECHNIQUE FOR IMPLANTATION OF A MITRAL VALVE HOMOGRAFT
}

\author{
José M. Revuelta, MD, José M. Bernal, MD, and José M. Rabasa, MD, Santander, Spain
}

The first attempts to replace atrioventricular valves with total or partial mitral valve homografts were performed on dogs in 1954. Further clinical and experimental studies were unsatisfactory, and homograft replacement of the mitral valve was eventually abandoned. By contrast, aortic homografts have been widely considered the best substitutes for aortic valve replacement since the first successful implantation of an aortic valve homograft was reported by Ross ${ }^{1}$ in 1962. Experience in the field of aortic homografts during the past 30 years, increasing availability of homograft valves resulting from the development of heart transplantation programs, and the fact that prosthetic mitral valve replacement and reconstructive operations seem to have reached the ceiling have contributed to the resurgence of interest in mitral valve homografts. Major impediments related to technical difficulties remain in the widespread use of homograft replacement of the mitral valve. Reimplanted papillary muscles are subjected to systolic pressure of the left ventricle, with risk of dehiscence. Tailoring of the circumferential size of the graft and length of chordae tendinae may be another surgical problem. We describe a technique of transvalvular implantation of a cryopreserved mitral homograft leaving the whole mitral valve apparatus of the recipient.

A 64-year-old man with a history of essential hypertension was hospitalized because of progressive exertional dyspnea and pulmonary edema. Transthoracic echocardiography revealed severe mitral regurgitation with prolapse of the posterior leaflet caused by rupture of the main chordae with dilatation of the left ventricle and giant left atrium. Perioperative transesophageal echocardiography and examination of the mitral valve confirmed the diagnosis, demonstrating severe valvular lesions: rupture of the main chordae, prolapse of the posterior and anterior leaflets, and annular dilatation. A cryopreserved (3 months) mitral homograft, $31 \mathrm{~mm}$ in diameter, from a heart explanted during a transplantation was used for mitral valve replacement. The mitral valve apparatus was not resected, and native papillary muscles were used as reference points for adjustment of the length of the graft's papillary muscles. Each papillary muscle was then fixed to the corresponding recipient point with two terminolateral sutures (3-0 polypropylene) with pledgets (Fig. 1). Two reference sutures were placed in both trigones; these were used as a guide when the graft anulus was fixed to the recipient anulus. A reference suture was also placed in the

From the Department of Cardiovascular Surgery, Hospital Universitario Valdecilla, Universidad de Cantabria, Santander, Spain.

Accepted for publication July 27, 1995.

J Thorac Cardiovasc Surg 1996;111:281-2

Copyright (C) 1996 by Mosby-Year Book, Inc.

$0022-5223 / 96 \$ 5.00+0 \quad \mathbf{1 2 / 5 4 / 6 8 2 0 0}$ middle part of the posterior leaflet. The mitral valve was preserved, and implantation of the homograft around the anulus was completed with a running suture (3-0 polypropylene). These sutures included the patient's anulus, the free edge of the native leaflet tissue, and the graft anulus. The annular suture was supported with a $31 \mathrm{~mm}$ Duran flexible annuloplasty ring (Medtronic Cardiovascular Surgery, Heart Valve Division, Minneapolis, Minn.). After discontinuation of cardiopulmonary bypass, transesophageal echocardiography showed proper functioning of the graft without prolapse and with an effective valve area of $2.5 \mathrm{~cm}^{2}$. Atrial fibrillation occurring after operation reverted to sinus rhythm with amiodarone. The patient was discharged on the eighth postoperative day and was given antiplatelet therapy for 3 months. At present, 10 months after operation, the patient is free of symptoms. Transthoracic echocardiography showed mild mitral incompetence caused by prolapse of the anterior leaflet with a normal left ventricle.

Technical difficulties in the implantation of the subvalvular apparatus, proper measurement of the graft, and early dehiscence of the reimplanted papillary muscles have been major impediments in the widespread use of human mitral valves. In our opinion, the intertrigonal distance, rather than the intercommissural distance, is the most suitable measurement for determining the size of the homograft. ${ }^{2}$ The site of implantation of the heads of the graft's papillary muscles is an important-and still unresolved-technical aspect. Knowledge gained through reconstructive operations of the mitral valve allow use in practice of the experience acquired in chordal shortening or replacement. On the other hand, native chordae tendinae can be used as reference points during implantation of the homograft when the whole mitral valve apparatus is preserved.

Dehiscence of the reimplanted subvalvular apparatus is the main postoperative failure in mitral valve homografting. In 1985, Sievers and colleagues ${ }^{3}$ reported the cases of three patients who needed urgent reoperation for severe mitral insufficiency caused by ruptured chordae (two cases) and ruptured graft papillary muscle (one case) at 2 , 9 , and 44 months after mitral homograft replacement. Acar and coworkers ${ }^{2}$ have used glutaraldehyde fixation in the papillary muscles of the homograft to minimize the risk of necrosis. Chemical fixation with glutaraldehyde, however, prevents cellular integration of the homograft which is the main advantage of the clinical use of human valves. Perhaps for this reason, chemical fixation of the graft has been recently abandoned. In our experience, implantation of papillary muscles has been carried out successfully, first in a sheep model ${ }^{4}$ and subsequently in human beings. ${ }^{5}$ Although papillary muscles have been inserted in a laterolateral position, ${ }^{2}$ terminolateral implantation seems to be more appropriate because the apex of the papillary muscle (site of insertion of the chordae tendineae) is the area of the greatest strength to support 


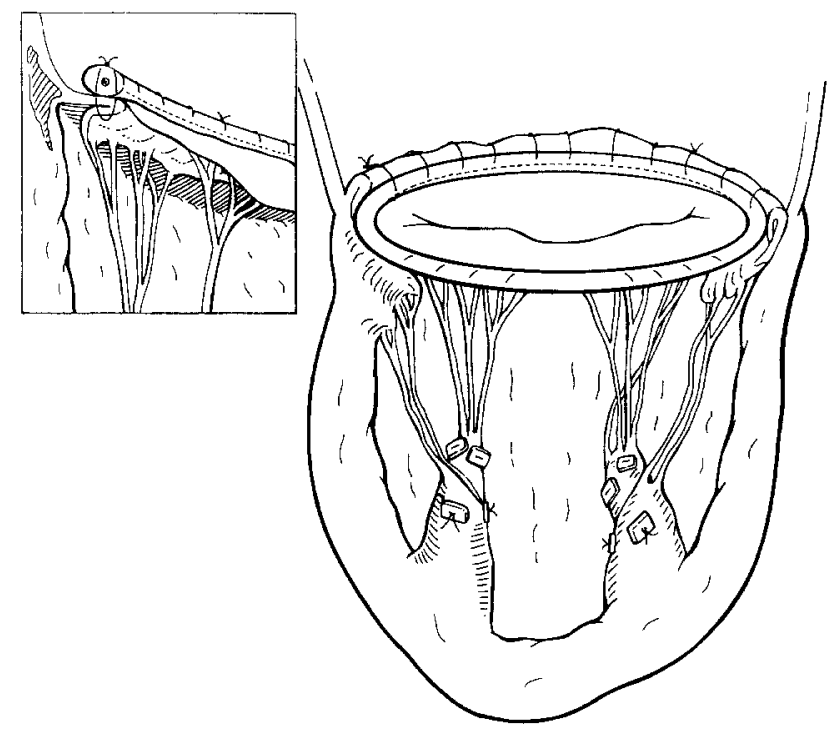

Fig. 1. Mitral homograft implantation preserving the entire native valve apparatus. Notice the terminolateral implantation of the papillary muscle.

the tension of the sutures. On the other hand, preservation of the native valvular apparatus aids in diminishing tension on the homograft. Ring annuloplasty ensures that annular reduction is carried out on a resistant tissue, reducing suture tension on the graft anulus, which may cause tearing and perivalvular dehiscence.

Although the interest in homograft replacement of atrioventricular valves has resumed in recent years, implantation of a mitral valve homograft is a complex operation that entails a risk of dehiscence of the reimplanted papillary muscles. Technical advances may contribute to expand the clinical use of mitral valve homografts in selected patients. Long-term stability of the results obtained, however, remains to be confirmed.

\section{REFERENCES}

1. Ross DN. Homograft replacement of the aortic valve. Lancet 1962;2:487.
2. Acar C, Farge A, Ramsheyi A, et al. Mitral valve replacement using a cryopreserved mitral homograft. Ann Thorac Surg 1994;57:746-8.

3. Sievers HH, Lange PE, Yankah AC, Wessel A, Bernhard A. Allogenous transplantation of the mitral valve: an open question. Thorac Cardiovasc Surg 1985;33: 227-9.

4. Revuelta JM, Cagigas JC, Bernal JM, Val F, Rabasa JM, Lequerica JM. Partial replacement of the mitral valve by homograft: an experimental study. J THORAC Cardiovasc Surg 1992;104:1274-9.

5. Revuelta JM, Bernal JM, Rabasa JM. Partial homograft replacement of mitral valve. Lancet 1994;334: 514. 